concentration of salt in the sweat may be one aetiological factor of prickly heat, but they have not yet proved the point. They also believe that the salt intakes of their subjects did not differ significantly, and therefore that those with a high concentration of salt in the sweat and urine might have adrenocortical hypofunction or fatigue. No relationship has so far been observed between prickly heat and heat exhaustion induced by lack of salt. Loewenthal and his colleagues appear to be well placed to elucidate these matters once and for all ; it is good to learn also that they will attempt to study sweat-salt levels and any predisposition to prickly heat in families of patients with mucoviscidosis.

\section{Disposal of the Dead}

The fact that the English coroners' system has existed since the twelfth century suggests to some people that it must have considerable vigour and adaptability. Others have contended that its natural end is nigh and that the animal should be put out of its misery. On balance the first view prevails. ${ }^{1}$ The council of the Coroners' Society, in a memorandum ${ }^{2}$ published last year, suggested improvements to bring the system up to date and, perhaps not surprisingly, considered it was capable of adaptation to present and future needs. Independent support came from the British Medical Association with publication of its report on the medico-legal investigation of deaths in the community. ${ }^{3}$ It put forward a considerable number of recommendations for bringing procedures into line with modern needs. The Home Secretary's announcement last week ${ }^{4}$ that he has decided to set up an inter-departmental committee on coroners' courts and related matters is therefore welcome. It is the more so in that this is the first time a committee has been appointed to inquire into the whole subject of disposal of the dead. Its terms of reference are:

"To review (a) the law and practice relating to the issues of medical certificates of the cause of death and for the disposal of dead bodies; and (b) the law and practice relating to coroners and coroners' courts, the reporting of deaths to the coroner and related matters, and to advise whether any changes are desirable."

The primary tasks before the committee are described in the announcement as:

"1. Examining the arrangements for issuing medical certificates of the cause of death and for ensuring that further investigation is carried out in appropriate cases. In this aspect of their work the committee will need to take account of recent criticisms that the law at present makes it too easy for homicide to go undetected.

" 2 . Considering whether the existing law and practice relating to coroners and coroners' courts provides the best basis for modern conditions for determining the cause of death. This will involve consideration of the procedures of the coroner, his jurisdiction, appointment, terms of service, etc."

The committee will also be considering the organization of forensic pathology and the medical certification necessary before cremation. The names of its members have yet to be announced.

Commenting on the B.M.A.'s report earlier this year a leading article ${ }^{5}$ referred to the unfortunate ambiguity that surrounds some of the terms governing a medical practitioner's relationship to the coroner, and it is to be hoped that the new committee will begin by getting some definitions straight. As the report points out, "sudden" death has never been defined and the idea of " unnatural " death has changed greatly over the centuries. In consequence doctors to-day are sometimes doubtful what their proper course is, and to their doubt anxiety may be added when the relatives have their own wishes about whether a case should or should not be reported to the coroner.

The suspicion that homicide may too often go undetected, as J. D. J. Havard ${ }^{6}$ has suggested, is something that the committee is being asked to examine in particular. According to the death certificates more than 100,000 persons are being certified dead in England and Wales each year without being seen after death by the certifying doctors. ${ }^{3}$ This number comprises about $25 \%$ of the total, but it is an improvement on the practice of only thirty years ago, when nearly $50 \%$ were not being seen after death. In accordance with the recommendations of several previous reports the B.M.A. reiterates the view that seeing the body after death should be an obligation on the certifying doctor. The difficulties of transport which used to be thought sufficient to relieve the doctor of compulsory attendance are now considered to have disappeared. There is a common law duty for every person about the deceased to notify the coroner of circumstances requiring the holding of an inquest. Statute law relies on death registration to ensure that an unnatural death is notified to the coroner. In practice direct report by the doctor or police is almost invariable. This procedure should have statutory sanction, and both the Coroners' Society and the B.M.A. consider that a duty should be cast on doctors, as well as others, to inform the coroner of deaths requiring medico-legal investigation. Delays before a certificate of disposal of the body is issued by the registrar can occur at present because his office may be open for only a few hours in each week, for the time within which a death must be registered is five days. Reduction of this time to 48 hours, and extension of the time during which the office is open, would be advisable if the suggestion is adopted that no embalming should be done until the certificate has been issued. Partial embalming is very commonly carried out, and it nullifies the tests for most poisons.

Determining the cause of death can pose a remarkably difficult problem to the coroner. One investigation showed, for instance, that unless a properly qualified and experienced pathologist carries out the necropsy the coroner will arrive at the wrong cause of death in at least one-third of cases. The Coroners Rules 1953, Rule 3 (a), recommend that postmortem examination should be made by a pathologist with suitable qualifications and experience and having access to laboratory facilities. It appears that there are still coroners who do not realize the vital importance of this rule. The coroner's power to order any registered medical practitioner to carry out a necropsy should be abolished and replaced by the requirement that only experienced pathologists should do the work. It is worth noting too that the conditions under which they have to work are too often deplorable. Much better mortuary facilities are urgently needed in many areas.

\footnotetext{
1 Brit. med. f., 1963, 2, 1603.

2 Memorandum prepared by Coroners' Society of England and Wales (approved 1962), 1963.

3 Deaths in the Community. British Medical Association, London. 1964. 2s. 6d. net.

- Brit. med. f., 1964, 2, 767.

- Ibid., 1964, 1, 854.

- Harvard, J. D. J., The Detection of Secret Homicide. London. 1960.

' Turkel, H. W., f. Amer. med. Ass., 1953, 153, 1086.
} 
The B.M.A.'s report and the Coroners' Society memorandum contain much else of value to any reconsideration of the coroners' system, including suggestions for modernizing the districts served by coroners. The interdepartmental committee will have the opportunity to examine all these matters, and its report will be awaited with interest.

\section{Inspired Patronage}

The Nineteenth Annual Report of the Nuffield Foundation, ${ }^{1}$ the first to appear since the death of Lord Nuffield and the last before the retirement of the Foundation's first director, Mr. Leslie Farrer-Brown, is a record of grants discerningly allocated both to established projects and to new investigations. The report includes details of the largest single grant yet made for medical research by the Foundation. Up to $£ 350,000$ has been given to the University of Liverpool to establish a Nuffield Unit of Medical Genetics, whose first director is to be Dr. C. A. Clarke, reader in medicine at the University. Liverpool is now recognized to be one of the foremost centres in this field, and the grant, which is to cover both the capital expenses of a building and the running costs up to the beginning of the university quinquennium in 1972-3, will enable the close links which already exist between scientists, clinicians, and hospitals in the city to become even stronger. It is planned to continue the work on haemolytic disease of the newborn by Dr. Clarke and Professor P. M. Sheppard, of the department of genetics, and to study, among other things, rheumatic fever, rheumatoid arthritis, duodenal ulcer, and schizophrenia.

A second large grant of particular interest is of $£ 50,000$ to the department of dental science at the Royal College of Surgeons for research into dental caries. The report points out that dental research was one of the Foundation's earliest interests, and that as long ago as 1946 it gave grants totalling $£ 90,000$ for this purpose. Recently, however, relatively few applications have been made for grants for dental research, and the trustees have therefore welcomed the opportunity for giving further help in this field. The grant will be used for establishing a colony of monkeys at the College's Buckston Browne Farm. The similarity between the teeth, oral bacterial flora, and dental caries in monkeys and in man makes these animals especially suitable for research into caries, particularly since they will also accept human diets.

The traditional interest of the Foundation in research into rheumatism is reflected in its sponsorship of two three-day residential conferences, the first in 1962 and the second in 1964, and seven new or renewed grants for workers in this field. A grant of $£ 34,740$ has been made to establish an Experimental Immunological Unit at the Middlesex Hospital Medical School. This will be directed by Dr. I. M. Roitt, who is to investigate whether a true rheumatoid factor and a chronic arthritis can be produced in a strain of mice that characteristically develop auto-antibodies spontaneously.

Other grants are distributed widely, ranging from industrial health and occupational hygiene schemes, an investigation into bronchitis in the steel industry, open-heart surgery, and the

1 The Nuffield Foundation Nineteenth Report for the Year Ended 31st March 1964. Oxford University Press. 1964. psychiatric problems of general practice. This year almost a quarter of the Foundation's grants have been allocated to the Commonwealth. A sum of $£ 80,000$ has been given to enlarge the Walter and Eliza Hall Institute of Medical Research in Melbourne, Australia, where the extensions will be named the Nuffield-Burnet Laboratories. There are also details of grants to extend a college of dentistry in Pakistan, to study steroids in Hong Kong, and to buy a new ambulance for Dominica.

\section{Infected Ascitic Fluid in Cirrhosis}

Two reports have again emphasized the importance of recognizing the syndrome of spontaneous peritonitis and bacteraemia caused by enteric organisms in patients with cirrhosis. Until recently this association had apparently been recorded only by French workers, but cases in Britain have now been reported by D. N. S. Kerr and his co-workers ${ }^{1}$ and in the U.S.A. by H. O. Conn. ${ }^{2}$ Bacteraemia in patients with cirrhosis is presumably caused by "shunting" of bacteria from the gut through abnormal vessels which communicate directly with the systemic circulation; this enables them to avoid the bacterial filter of the liver. It is also possible that the clearance of bacteria by the reticuloendothelial system is diminished in cirrhosis and that bacteria already trapped by the liver are re-excreted into ascitic fluid via hepatic lymph. Paracentesis with damage to the gut and release of enteric organisms may be another factor, though in some cases paracentesis has never been employed. A focus of intra-abdominal infection-for example of the small bowel or the bile ducts-is also occasionally found.

Peritonitis due to the multiplication of bacteria in ascitic fluid is often "silent" and little pain or rigidity is present. Fever of unknown aetiology is frequently seen in patients with cirrhosis and ascites, and unless it is considerable it can hardly be regarded as evidence of bacterial infection. But when bacteria enter the blood-stream there is usually evidence of hepatic encephalopathy together with high fever, leucocytosis, and hypotension. Both bacteraemia and peritonitis can be confirmed by blood culture and paracentesis. The ascitic fluid is turbid and contains more than 1,000 leucocytes per c.mm., while bacteria can be grown on culture. In Conn's cases three of five patients had Escherichia coli in the ascitic fluid, one had Streptococcus faecalis, and the other Aeromonas lignifaecens. The same organisms were found in the blood-stream, so that probably the initial event is a bacteraemia and the ascitic fluid is secondarily infected. Prompt recognition of this syndrome is essential, for, though the prognosis of the patient with ascites and liver failure is often poor, treatment with intraperitoneal and systemic antibiotics may be life-saving. Kerr and his colleagues have also suggested that the apparatus normally used for paracentesis is particularly apt to produce injury to the bowel and have designed a modified instrument to prevent this. Moreover, the dangers of paracentesis ${ }^{3}$ should not be forgotten and the procedure should be reserved for those patients refractory to full diuretic therapy or for those acutely distressed by gross ascites.

\footnotetext{
${ }^{1}$ Kerr, D. N. S., Pearson, D. T., and Read, A. E., Gut, 1963, 4, 394.

2 Conn, H. O., Ann. intern. Med., 1964, 60, 568.

s Brit. med. F., 1960, 2, 1002.
} 